\title{
Management of malignant pleural effusion
}

Pleural effusion is a common development in patients with cancer and causes significant morbidity. ${ }^{12}$ Systemic treatment may be appropriate in patients with chemosensitive malignancy but, for the majority of patients with recurrent effusion, some form of pleurodesis is warranted. The optimal method remains debatable and is often chosen on the basis of personal experience and opinion rather than objective data.

Temporary symptomatic relief may be provided by repeated needle thoracocentesis but this is only suitable in those patients with limited survival and slowly recurrent effusion. Most effusions reaccumulate within 1-3 days $^{3}$ and an attempt at ablation of the pleural space is required. Pleurectomy is the most radical and effective method but carries a high morbidity (23\%) and mortality $(10 \%) .{ }^{4}$ As the clinical goal is palliation with minimal inconvenience and discomfort to the patient, chemical pleurodesis is generally the preferred treatment.

Chemical pleurodesis aims to invoke a brisk, widespread inflammatory reaction of the pleura which heals by fibrosis with consequent obliteration of the pleural space. Success depends on adequate drainage of the pleural fluid, complete expansion of the lung, with apposition of the visceral and parietal pleurae and thereafter the introduction of an effective sclerosant. Drainage of the pleural space to dryness limits potential dilution of the sclerosant and allows the lung to re-expand. Thoracoscopic aspiration is most effective but most physicians use either intercostal tube drainage or needle aspiration and these two methods are currently being compared in a randomised study organised by the British Thoracic Society. Currently we recommend intercostal tube drainage, preferably with suction, until the pleural cavity is radiologically dry or drainage is less than $100 \mathrm{ml}$ fluid per day. Ultrasound or computed tomographic assisted drainage may be appropriate for those with loculated effusions. Complete re-expansion of the lung is necessary to achieve pleural symphysis and any persisting pneumothorax should be drained by suction. Failure of the lung to re-expand should direct the clinician away from chemical pleurodesis.

Several different sclerosants are available including tetracycline, bleomycin, and talc. Few randomised comparative trials with large patient numbers have been conducted, and this probably reflects the fact that designing trials in patients with malignant pleural effusions presents certain difficulties with regard to case selection and definition of outcome.

Tetracycline continues to be the most widely used sclerosant in the $\mathrm{UK}^{5}$ although its production is ceasing in the USA. ${ }^{6}$ Most studies quote a greater than $60 \%$ efficacy in malignant pleural effusion ${ }^{78}$; it has a proven safety record, is easy to use, and costs less than its main rivals. We use a dose of $3 \mathrm{~g}$ in $50 \mathrm{ml}$ normal saline based on animal studies comparing low and high dose tetracycline with quinacrine, nitrogen mustard, and bleomycin in which tetracycline at a dose of $35 \mathrm{mg} / \mathrm{kg}$ was the only agent to induce pleural fibrosis. ${ }^{9}$ The main side effect with tetracycline instillation is pain and we recommend administration of $30 \mathrm{ml} 1 \%$ lignocaine intrapleurally about 30 minutes before the procedure and premedication with morphine, 5-20 mg intramuscularly or intravenously as appropriate. After instillation the tube is clamped and the patient rotated from side to side for two hours to distribute the sclerosant throughout the pleural cavity. Suction is then reapplied for a further 24 hours and, provided no further fluid has reaccumulated, the drain is removed.

In this issue of Thorax (pp 790-793) Koldsland et al report a randomised prospective single centre comparative study of the treatment of chemical pleurodesis in malignant pleural effusions with the antimalarial drug mepacrine and the cytotoxic drug bleomycin, neither of which are used much in the UK. Mepacrine was $80 \%$ effective and bleomycin $50 \%$ effective at 30 days. This difference, of marginal statistical significance, is difficult to interpret and may reflect differences in management approach between the two sclerosants. Suction was applied two hours after instillation of mepacrine but not until 24 hours after bleomycin.

Ruckdeschel et $a l^{10}$ have recently conducted a prospective multicentre trial comparing $1 \mathrm{~g}$ of tetracycline with 60 units of bleomycin. They found the recurrence rate at 90 days was $30 \%$ for bleomycin and $53 \%$ for tetracycline. The mean time to recurrence was 48 days and 32 days respectively. Again interpretation is difficult as the recurrence rate with tetracycline was higher than in other published studies and that with bleomycin lower.

This year sees the withdrawal of Corynebacterium paroum which was enthusiastically advocated by its proponents. ${ }^{11}$ It was said to be less painful for the patient, effective in up to $90 \%$ of patients, and was even credited by some as having antitumour activity. ${ }^{12}$ Despite this it did not receive wide enough use to justify continued production (personal communication, Wellcome). New biological agents are appearing and research is proceeding with adoptive immunotherapy using interleukins to induce lymphocyte activated killer cells within the malignant effusion. ${ }^{13} 14$

The role of thoracoscopy with tube drainage and talc poudrage as a primary procedure has been the focus of debate. ${ }^{15}$ It is useful in establishing a diagnosis and has the advantage of being more definitive. However it is more invasive, more expensive, requires a higher level of technical skill, is not universally available, and has a higher attendant morbidity and up to $5 \%$ mortality. ${ }^{16}$ Impressive results have been reported by Webb et al ${ }^{17}$ who achieved $100 \%$ effectiveness in preventing recurrence of effusion in 34 patients ( 28 with malignant disease) using a slurry of iodised talc administered through an intercostal tube. The procedure was well tolerated and without severe side effects although both adult respiratory distress syndrome ${ }^{18}$ and acute pneumonitis ${ }^{19}$ have been described following intrapleural administration of talc.

For those in whom the lung fails to re-expand, precluding pleurodesis, a pleuroperitoneal shunt may be useful. Experience with the Denver shunt suggests it is also useful in providing symptomatic relief in cases of failed medical management and particularly useful in the management of chylothorax. ${ }^{20}$ Concern about peritoneal seeding appears to be realistic but was seen in only two of 40 patients. $^{21}$

For the majority of patients intercostal tube drainage followed by chemical pleurodesis remains the treatment of choice. Failure of chemical pleurodesis may be due to 
extension of the malignant disease process but often reflects failure to adequately drain the pleural space, expand the lung, and appose the pleural surfaces. More invasive procedures should be reserved for those in whom the diagnosis is uncertain or in whom the lung fails to expand. On the present evidence we feel that, if a fully expanded lung in a dry pleural cavity can be achieved, tetracycline should be the sclerosant of choice on the grounds that it is simple to instil, safe, well tolerated by the patient, known to induce pleural fibrosis, and inexpensive.

PT REID

RM RUDD

London Chest Hospital,

Bonner Road,

Reprint requests to: Dr RM Rudd

1 Friedman MA, Slater E. Malignant pleural effusion. Cancer Treat Rev 1978;5:49-66.

2 Ruckdeschel JC. Management of malignant pleural effusion: an overview. Semin Oncol 1988;15(Suppl):24-8.

3 Anderson CB, Philpott GW, Ferguson TB. The treatment of malignant pleural effusion. Cancer 1974;33:916-22.

4 Martin N, Bains MS, Beattie EJ. Indications for pleurectomy in malignant pleural effusions. Cancer 1975;35:734-8.

5 McApline LG, Hulks G, Thomson NC. Management of recurrent malignant pleural effusion in the United Kingdom: survey of clinical practice. Thorax 1990;45:699-701.

6 Heffner JE, Unruh LC. Tetracycline pleurodesis adios, farewell, adieu (editorial). Chest 1992;101:5-7.

7 Bayly TC, Kisner DL, Sybert A, McDonald JS, Tsou E, Schein PS.
Tetracycline and quinacrine in the control of malignant pleural effusions. A randomised trial. Cancer 1978;41:1188-92.

8 Zalonik AJ, Oswald SG, Langin M. Intrapleural tetracycline in malignan pleural effusions: a randomised study. Cancer 1983;51:752-3.

9 Sahn SA, Good JT. The effect of common sclerosing agents on the pleural space. Am Rev Respir Dis 1981;124:65-7.

10 Ruckdeschel JC, Moores D, Lee JY, Einhorn LH, Mandelbaum I, Koeller J, et al. Intrapleural therapy for malignant pleural effusions: a randomised comparison of bleomycin and tetracycline. Chest 1991;100: 1528-35.

11 Seaton A, Seaton D, Leitch AG. Crofton and Douglas's respiratory diseases. 4th edn. Oxford: Blackwell, 1989.

12 McLeod DT, Calverly PM, Millar, Horne NW. Further experience of Corynebacterium in malignant pleural effusion. Thorax 1985;40:515-8.

$13 \mathrm{Li}$ DJ, Wang YR, Tan XY, Wang HZ, Yao XD, Ba DN. A new approach to the treatment of malignant effusions. Chinese Med $f$ 1990;103 998-1002.

14 Yasumoto $\mathrm{K}$, Ogura $\mathrm{T}$. Intrapleural application of recombinant interleukin-2 in patients with malignant pleurisy due to lung cancer. A multi-institutional co-operative study. Biotherapy 1991;3:345-9.

15 Aelony Y. Thoracoscopic talc poudrage comparison with tetracycline and use in Hodgkin's disease (Letter). Chest 1992;101:1922-33.

16 Ohri SK, Oswal SK, Townsend ER, Fountain SW. Early and late outcome after diagnostic thoracoscopy and talc pleurodesis. Ann Thorac Surg 1992;53:1038-41.

17 Webb WR, Ozmen V, Moulder PV, Shabahang B, Breaux J. Iodized talc pleurodesis for the treatment of pleural effusions. $\mathcal{F}$ Thorac Cardiovas Surg 1992;103:881-6.

18 Rinaldo JE, Owens GR, Roger RM. Adult respiratory distress syndrome following intrapleural instillation of talc. $₹$ Thorac Cardiovasc Sur 1983;85:523-6.

19 Bouchama A, Chastre J, Gaudichet A, Soler P, Gilbert C. Acute pneumonitis with bilateral pleural effusion after talc pleurodesis. Ches 1989;86:795-7.

20 Milsom JW, Kron IL, Rheuban KS. Chylothorax: an assessment of current surgical practice. $\mathcal{F}$ Thorac Cardiovasc Surg 1985;89:221-7.

21 Wong PS, Tsang V, Kaplan D, Goldstraw P. Long term follow up of pleuroperitoneal shunts for malignant pleural effusion (abstract). Thorax 1992;47:861-2. 